Nẻe en France, Dominique O'Neill a longtemps vécu en Oregon et en Colombie-Britannique. Étudiante au Centre universitaire David Thompson, à Nelson, en Colombie-Britannique, elle suit des cours de poésie à la Kootenay School of Writing où elle est l'étudiante du poète Fred Wah, lui-même disciple du poète américain Charles Olson, grand prêtre des New American Poetics. Cette poétique du temps et du lieu demande que l'on revienne aux sources premières, aux souches. Il faut donc qu'elle redécouvre cette langue maternelle quasiment oubliée. Ce pèlerinage la mène d'abord en France, où, après vingt ans d'absence, elle retrouve sa famille, et ensuite au Collège universitaire Glendon et à l'Université de Toronto où elle obtient ses diplômes en littérature française.

Elle enseigne aujourd'hui le français au Collège Universitaire Glendon.

Ses poèmes en anglais ont paru dans diverses revues littéraires mais, hormis quelques poèmes parus dans Élixir et le Glendon Yearbook, elle n'a pas encore publié en français.

\title{
* *
}

pour mon père

$J_{\text {e te salue, Pays }}$

où se sont évanouis mes ancêtres

vaincus

dans l'arène impitoyable du temps

ne laissant pour tout message

que leur nom sur la pierre

en forme de croix.

Je te salue

Pays où je vis pour la première fois

laurore se lever sur la liesse des flots.

Pays où je ne vis plus,

ravie de tes rives

par la caravelle de l'exil,

ta mer pourtant tangue dans ma poitrine. 
Mais voici que le ressac des jours de neige et des sourdes nuits sans lune me jette sur tes grèves, et ton sable le lit de tant de rêves et le choeur de tant d'oiseaux dans mes songes

et l'absence une pierre par ta main lapidée.

Tant de rives parcourues qui menaient loin de toi tant de songes meurtris, de paroles fanées aux lèvres du jour alors qu'au petit matin tu sombrais et ma voix dans le vide comme l'appel d'un cor.

Pays redécouvert, à quoi rêves-tu sous mes yeux ardents assoupi de toute ta blondeur?

Pourquoi n'ai-je vécu contre ton flanc comme l'aïeule vaquant au quotidien entre l'âtre et le puits sarclant le champ avant de s'y coucher? toi qui offres la coupe du festin et la floraison de tes landes à qui de toi naquit.

Je te dresse aujourd'hui des autels pour des rites de coquillages. Je te façonne des offrandes de fleurs sauvages et d'aiguilles de pin et murmure des incantations pour conjurer le temps.

Moi qui troquerais toutes les cocardes de mes mots pour un tamaris rose sous le vent de midi quelques oeillets de dune ou un sourire de ceux qui ne m'attendent plus. 


\section{Hiver}

Tiens, c'est l'hiver.

Regarde les druides qui passent

avec leurs serpes et leurs fagots

et les mots s'éparpillent

comme les feuilles d'automne sur les chemins d'hier.

***

pour Paul

Oì le ciel sera le livre du poète

La Seine son lit de mort

Et le désespoir en festons sur l'ensemble.

*

\section{Passage}

Domaine des songes de lune et de vent

O souffle silencieux qui creuse et nourrit à la fois

Solitude d'un espace nu où l'empreinte du pied féconde la poussière Comme si chaque parole proférée était une pierre quil ferait le gue entre mot et mort entre vie et vide. 